\title{
Methodology for the Quantification of the Impact of Weather Forecasts in Predictive Simulation Models
}

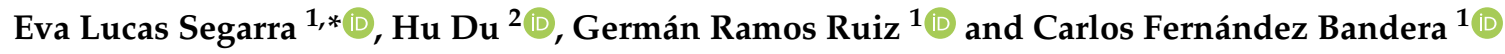 \\ 1 School of Architecture, University of Navarra, 31009 Pamplona, Spain; gramrui@unav.es (G.R.R.); \\ cfbandera@unav.es (C.F.B.) \\ 2 Welsh School of Architecture, Cardiff University, Bute Building, King Edward VII Avenue, Cardiff, \\ Wales CF10 3NB, UK; DuH4@cardiff.ac.uk \\ * Correspondence: elucas@unav.es; Tel.: +34-948-425-600 (ext. 803126)
}

Received: 30 January 2019; Accepted: 1 April 2019; Published: 5 April 2019

\begin{abstract}
The use of Building Energy Models (BEM) has become widespread to reduce building energy consumption. Projection of the model in the future to know how different consumption strategies can be evaluated is one of the main applications of BEM. Many energy management optimization strategies can be used and, among others, model predictive control (MPC) has become very popular nowadays. When using models for predicting the future, we have to assume certain errors that come from uncertainty parameters. One of these uncertainties is the weather forecast needed to predict the building behavior in the near future. This paper proposes a methodology for quantifying the impact of the error generated by the weather forecast in the building's indoor climate conditions and energy demand. The objective is to estimate the error introduced by the weather forecast in the load forecasting to have more precise predicted data. The methodology employed site-specific, near-future forecast weather data obtained through online open access Application Programming Interfaces (APIs). The weather forecast providers supply forecasts up to 10 days ahead of key weather parameters such as outdoor temperature, relative humidity, wind speed and wind direction. This approach uses calibrated EnergyPlus models to foresee the errors in the indoor thermal behavior and energy demand caused by the increasing day-ahead weather forecasts. A case study investigated the impact of using up to 7-day weather forecasts on mean indoor temperature and energy demand predictions in a building located in Pamplona, Spain. The main novel concepts in this paper are: first, the characterization of the weather forecast error for a specific weather data provider and location and its effect in the building's load prediction. The error is calculated based on recorded hourly data so the results are provided on an hourly basis, avoiding the cancel out effect when a wider period of time is analyzed. The second is the classification and analysis of the data hour-by-hour to provide an estimate error for each hour of the day generating a map of hourly errors. This application becomes necessary when the building takes part in the day-ahead programs such as demand response or flexibility strategies, where the predicted hourly load must be provided to the grid in advance. The methodology developed in this paper can be extrapolated to any weather forecast provider, location or building.
\end{abstract}

Keywords: weather forecast uncertainty; building energy model; building simulation; energy flexible buildings; model predictive control

\section{Introduction}

The European Energy Efficiency Directive establishes a set of binding measures to help the EU reach its 20\% energy efficiency target by 2020 [1]. Under the Directive, all EU countries are required to use energy more efficiently at all stages of the energy chain, from production to final consumption. 
By taking into account meteorological forecasts, building energy demand response solutions enable end users to reduce energy consumption, improve their thermal comfort conditions, increase energy grid efficiency and contribute to the penetration of renewable energy. A review by Lazo et al. [2] shows that energy management optimization with weather forecasting can generate $15-30 \%$ savings in most cases. At the individual building level, using both thermal and electric load prediction technologies with weather forecasting could optimize energy demand, storage and supply, thus reducing costs and greenhouse gas emissions. Furthermore, the use of weather forecast allows the building to adapt better to the climate of the near future leading the building to be more resilient to increasing extreme weather events, which has become essential to reduce the climate change effects [3,4].

One such energy management optimization strategy is model predictive control (MPC), around which current research efforts are evolving. It has shown a high theoretical potential for energy savings and improved indoor climate compared to conventional systems operation [5-11] and it allows the building to be part of demand response or flexibility scenarios [12-14]. However, it must be taken into account that some uncertainties are inherent to this predictive control:

- Simulation model accuracy: Previous work from authors have developed a calibration methodology to get accurate simulation models and predictions [15-17].

- The correct initialization on the simulation model is crucial to get accurate results, which has been studied as well by the authors in [15-17].

- MPC requires an optimization process that also has an inherent uncertainty. In [18], the authors have proposed a methodology to measure the accuracy of the optimization.

- Occupancy and user behavior, which is a stochastic and complex to be predicted parameter.

- Weather forecast that corresponds with the objective of this paper: the quantification of the weather forecasts' errors and their effect on the indoor climate conditions and energy demand in a predictive energy model.

Although weather forecast parameters have a significant influence on the predictive models, especially outdoor temperature [19-21], they have an ancillary treatment in the literature [22] and we can find only a few articles where the effect of weather forecast uncertainty is analyzed and quantified: Henze et al. [23] analyze the effect of the uncertainty using different weather prediction models on the performance of a predictive control concept. The conclusion is that it takes elementary short-term prediction models to realize almost all of the theoretical potential of the predictive optimal control technique. The findings of Oldewurtel et al. [24] suggest that a stochastic model predictive control (SMPC) strategy, which can directly account for the uncertainty of the weather forecast in control decisions, outperforms current control systems. It was also shown that the SMPC performed better using a complex weather prediction model compared to simple models. Zhao et al. [25] proposed a load forecasting method and tested it in an office building located in Tianjin, China, and analyzed the influence of weather forecast precision. They concluded that it had a slight effect on the proposed model: when the forecast error of temperature is $1.68^{\circ} \mathrm{C}$, the Mean Absolute Relative Error (MARE) of the 24-h ahead cooling load model for the testing period increases $1.56 \%$.

The common approach of most of these studies is that they use weather prediction models based on previous registered weather data that are not capable of dealing with changing future weather factors. Nowadays, there are many established weather forecast services providers that have made some of their data freely available through APIs (Application Programming Interface). The reason why this data is not usually used is that often there is a missing link between the weather forecast provider and the building energy management system [26]. Previous research from authors [26-28] demonstrated a novel approach that develops a Representational State Transfer (REST) API for users to obtain site-specific historical and near-future weather forecast data in Energy Plus Weather File (EPW) format for building simulation using the free online toolchain.

Many of these providers also offer forecasts more than 1 day-ahead (up to a 10-day weather forecast, i.e., provide forecast weather data predicted 10 days before), although its accuracy decreases as time moves further forward [28]. This longer time horizon weather forecast approach is applicable 
to the growing electricity futures market, where electricity is purchased for longer periods of time than the usual daily market [29]. It allows for having a stable price for a certain period of time, avoiding high variations in the prices in the daily and intraday electricity markets. In an MPC based on a weather forecast scenario, better planning and anticipation is enabled, which is an advantage for the energy system and for the building's energy management since its energy purchase risk is shortened.

The benefits of using simulation models for predictive strategies in MPC, demand response, flexibility and future markets are clear but uncertainty in weather forecast, among others, is inherent to these scenarios. This paper shows a methodology to quantify the impact of the error generated by specific location weather forecasts in a building's indoor climate conditions and energy load predictions. This methodology, which can be applied to any building in any location, is based on previous recorded information of real weather data from a near weather station and forecast weather data from a specific open access provider. As an application of the methodology, the paper also proposes a novel hour-by-hour error map of energy demand predictions that complements the hourly profile that shows the building's flexibility capacity used in demand response and flexibility scenarios [12,30] providing information on the estimated error for each hour due to weather forecast.

The rest of the paper is structured as follows: Section 2 presents the test site description of the case study used in this research. The methodology is described in Sections 3 and 4: Section 3 presents the weather files creation for both real and forecast data and Section 4 explains the simulation model process and the error metrics used for the quantification of the error in the outdoor and indoor temperature and building's energy demand. Section 5 shows and discusses the results obtained for this case study. In Section 6, an application of this methodology for model predictive control (MPC) and building energy flexibility is exposed. Finally, Section 7 presents the conclusions where the main results are emphasized.

\section{Test Site Description}

In order to carry out this research, the administrative building of the Architecture School at the Universidad de Navarra in Pamplona (Spain) was chosen to be the case study. This building was built in 1974 and it is mainly used as an administration building and by postgraduate students of the School of Architecture.

It is a 760-square-meter single-storey building with a concrete structure. The interior and exterior walls are built of red brick fabric and the windows, with aluminum frames, were installed in situ with an air chamber. Figure 1 shows the building's outdoor photograph, the space allocation and the simulation model, which has been divided into 25 thermal zones, one for each room. They all have Heating, Ventilation and Air Conditioning (HVAC) systems except for the bathrooms (TZ9 and TZ23), the HVAC room (TZ13) and the north corridor (TZ10). 

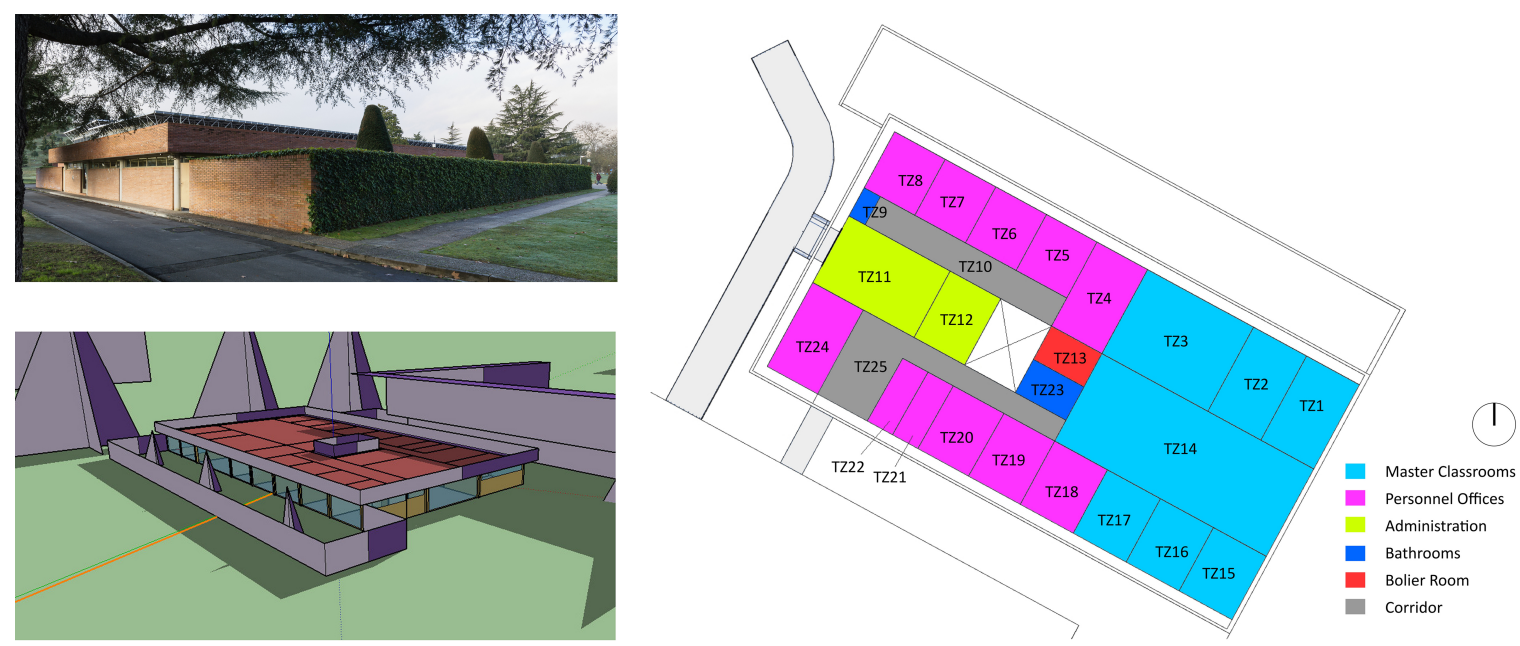

Figure 1. Building's outdoor photograph (above left), simulation model image from OpenStudio [31] (below left) and thermal zones allocation (right).

In order to develop the simulation model, the first step is the definition of the baseline model by introducing its geometry, geolocation and orientation. The EnergyPlus [32,33] engine, which complies with the requirements of EU Directive 2010/31/EU [34], is used for the model's development (idf) and the energy simulations.

For the building envelope parameters' definition, a calibrated model that represents the accurate thermal dynamics of the real building is used. The calibration process is based on the author's previous work [15-17]. The resulting calibrated model complies with the international quality standards International Performance Measurement and Verification Protocol (IPMVP) [35], Federal Energy Management Program (FEMP) [36,37] and American Society of Heating, Refrigerating and Air-Conditioning Engineers guidelines (ASHRAE) [38,39]. In order to produce the correct model initialization, the measured data from the installed temperature sensor network (23 temperature sensors) are introduced in the model as thermal history.

For the correct simulation of the model, the internal loads are defined and adjusted to the real ones. The occupancy of the building is established based on the personnel surveys undertaken. Data from the two electricity meters installed in the building are used to define the load generated by the lights and the equipment. The HVAC systems follow the Spanish Regulation of Thermal Installations in Buildings (RITE) [40] and have a heating temperature set-point of $21^{\circ} \mathrm{C}$ and a cooling temperature set-point of $25^{\circ} \mathrm{C}$. The building has an office schedule and is used from 8:00 a.m. to 8:00 p.m. during weekdays and from 8:00 a.m. to 2:00 p.m. on Saturdays. The building is not used on Sundays.

\section{Weather Data Processing}

Figure 2 shows the methodology used for the weather data processing. Using as inputs the measured and forecast weather data, the different weather files are generated.

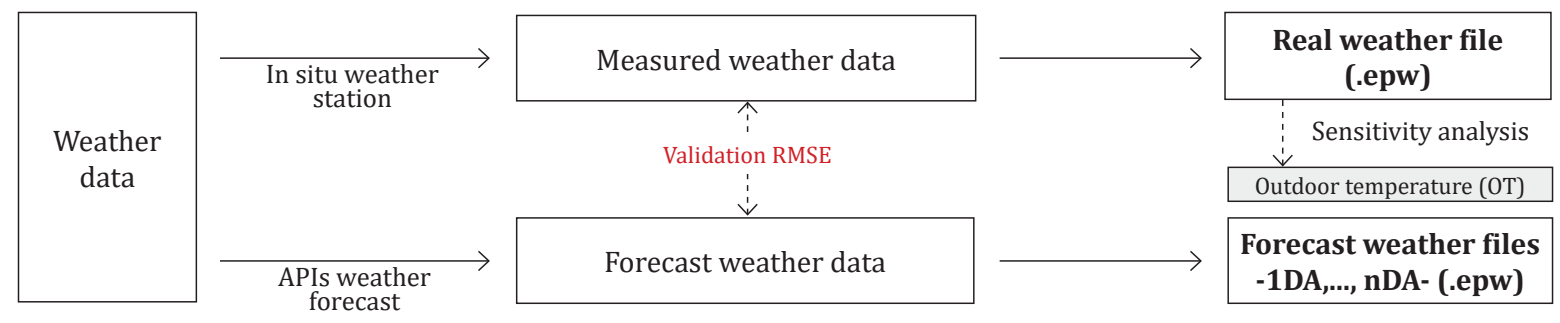

Figure 2. Weather data processing scheme. 


\subsection{Weather Files Generation}

This methodology needs the preparation of different weather files for the real weather data, which will be used as a benchmark, and for each day-ahead of forecast weather data (1DA-nDA). The Weather Converter [41] tool, provided as an auxiliary program by EnergyPlus, is used for the creation of these weather files. It translates and extends typical weather data into the EnergyPlus format (.epw) making the necessary calculations for unavailable data.

Measured values are used to develop the real weather file. The more parameters available, the more accurate the weather file will be. For the case study, the weather station installed in the building is used and provides: outdoor temperature $\left({ }^{\circ} \mathrm{C}\right)$, wind direction $\left({ }^{\circ}\right)$, wind speed $(\mathrm{m} / \mathrm{s})$ and relative humidity (\%). The rest of the weather parameters are provided by a nearby weather station belonging to the Navarra Government: global solar radiation $\left(\mathrm{W} / \mathrm{m}^{2}\right)$, diffuse solar radiation $\left(\mathrm{W} / \mathrm{m}^{2}\right)$, rainfall $\left(\mathrm{L} / \mathrm{m}^{2}\right)$ and atmospheric pressure (mbar). This weather station is located in the same city, about $2.5 \mathrm{~km}$ away from the building of study.

For the forecast weather files, the data is obtained using the methodology presented by the authors in [26-28]. This methodology, based on the free online toolchain, develops a REST API for users that obtains site-specific near-future forecast weather data in EPW format from cost-free access providers. Table 1 has listed six API weather forecast providers known to the authors that supply free available data for Pamplona, Spain. Each provider uses different data sources and forecasting models and the same provider can use different weather data sources that are aggregated together to provide the most accurate forecast possible for a given location. For this reason, this methodology should be applied for each specific weather forecast provider or location.

Table 1. Weather forecast providers.

\begin{tabular}{lccc}
\hline API Provider & Forecast & Interval & Format \\
\hline aemet [42] & Next 7-day & hourly & JSON \\
met.no [43] & Next 10-day & hourly & XML \\
openweathermap [44] & Next 5-day & 3-hourly & XML/ JSON \\
weatherbit [45] & Next 5-day & 3-hourly & JSON \\
dark sky [46] & Next 7-day & hourly & JSON \\
wunderground [47] & Next 10-day & hourly & XML/ JSON \\
\hline
\end{tabular}

Since the weather forecast APIs are not developed for the building simulation industry, not all the parameters needed for simulation are immediately or open access available from the APIs' standard responses. Key parameters such as temperature, relative humidity, wind speed and wind direction are included in the open access API forecast response. However, a key parameter as it is the solar radiation (direct and diffuse) is not available from APIs, or not for free, according to the knowledge of the authors. In the literature, some studies use relative humidity and sun position to calculate solar radiation [48,49]. However, previous work from authors [27], where this method was applied to generate direct and diffuse solar radiation, did not produce good accuracy between forecast and observed data. The particularities of the solar radiation forecast and its difficulties to be obtained require a dedicated study where its calculation and impact can be studied. For this reason, in this study, the solar radiation was not included as a forecast parameter and the data from Navarra Government weather station was used in the weather files.

In this research, the period of study comprises three months, from 6 February 2018 to 6 May 2018. The six weather forecast APIs from Table 1 are analyzed and compared with the observation data from the in situ weather stations. In order to quantify the difference, the root mean square error (RMSE, Equation (1)) is calculated between the observed data and the forecast data for 1 day-ahead prediction horizon. Figure 3 shows the comparison done for the four weather parameters directly available provided by the APIs: temperature, relative humidity, wind direction and wind speed. The example 
size ( $n$ ) of the study is 2160 data points, covering hourly data for 90 days in the case of hourly forecast APIs (1-4) and 720 data points for the case of 3-hourly forecasts of APIs 5 and 6.
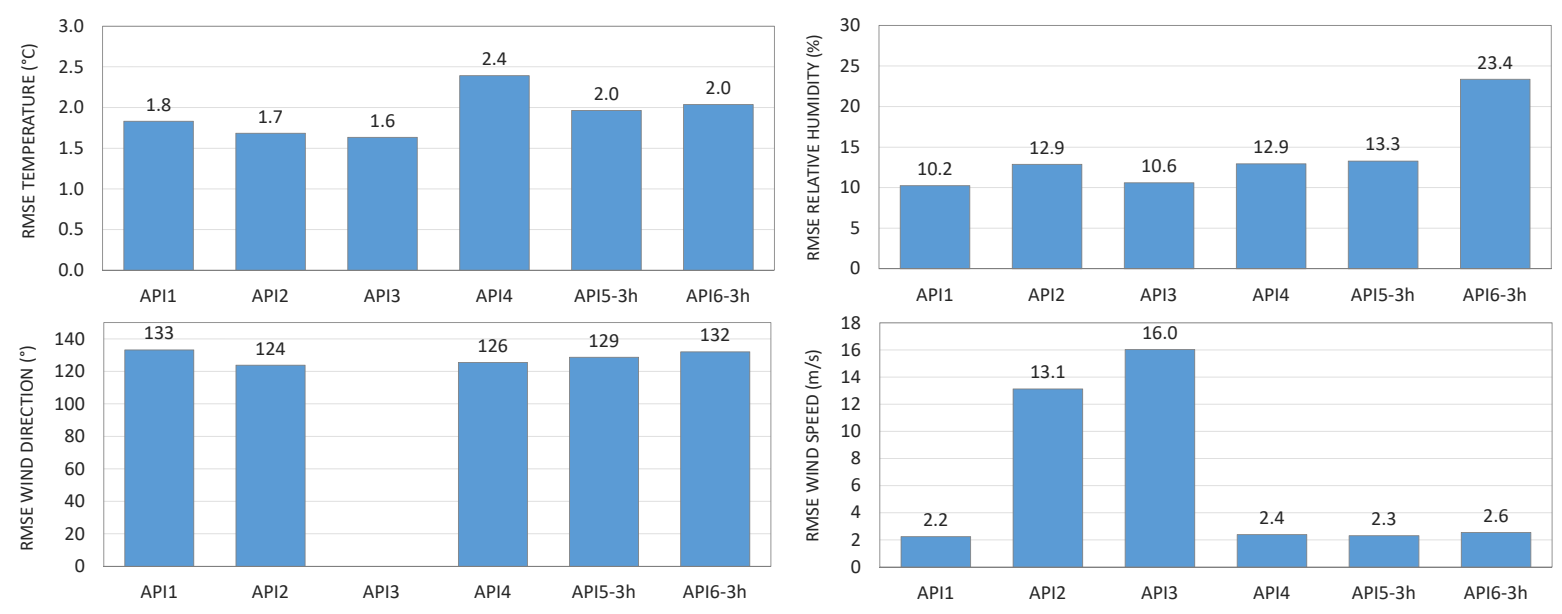

Figure 3. Root Mean Square Error (RMSE) for 1 day-ahead prediction horizon between observation and forecasts from different weather providers (from 6 February 2018 to 6 May 2018). Above left: RMSE temperature; above right: RMSE relative humidity; below left: RMSE wind direction; below right: $R M S E$ wind speed.

For this case study, the hourly weather forecast from DarkSky [46] is selected, which correspond with API1 in Figure 3, as it provides hourly 7 day-ahead forecast for the four parameters required.

In the forecast weather files' construction, the first step was the validation of the available data. Within the 90-day period (6 February 2018 to 6 May 2018), some days were removed from the study because there were no available forecast data for the 7 day-ahead horizon predictions. On the other hand, the three months' period was divided into weeks and the final period of study is composed of ten complete weeks (Monday to Sunday) from 12 February 2018 to 22 April 2018 (70 days).

All the weather files have real data information from 1 January 2018 to 11 February 2018 to maintain the same conditions in the previous period. From 12 February 2018 to 22 April 2018, each forecast weather file has its own forecast data for outdoor temperature, relative humidity, wind direction and wind speed. The rest of the weather parameters are data from the weather stations. Figure 4 explains how the different forecast weather files are built. For the 1-day forecast weather file (grey blocks), all the days have the forecast data predicted the midnight of the previous day. Similarly, 2-day forecasts (red blocks) have the forecast data predicted the midnight of two days before, and so on up to 7-day forecasts (brown).

Taking advantage of the available 7-day forecast, a combined weather file (called CMB hereinafter and represented in a black box in Figure 4) with a 1-week forecast is proposed in this case study. This weather file was created week by week, where every Monday has a 1-day forecast (forecast data predicted one day before), every Tuesday has a 2-day forecast (forecast data predicted two days before), and so on, up to Sundays, which have a 7-day forecast (forecast done seven days before). The purpose of this combined forecast week analysis is to investigate the impact of the energy performance caused by a weather prediction made one day for the following seven days.

Figure 5 shows the comparison between the outdoor temperature observation and the 1-day forecast (above) and the 7-day forecast (below) over the whole period of study. It shows that the 1-day forecast is fairly close to observations, but 7-day forecast generates significant differences when compared with observed data. To understand the accuracy of the 1-, 2-, 3-, and up to 7-day forecasts, the RMSE between the observed temperatures and forecasts are compared in Figure 6 . It shows that 1-day and 2-day forecasts have the best accuracy, and 3-4 day forecasts are reasonably accurate. The accuracy decreases as the time span increases. The difference in the RMSE among different days 
forecasts is quite clear as can be seen in Figure 6. This measurement makes the sample selected for the paper representative of the phenomena we try to show.

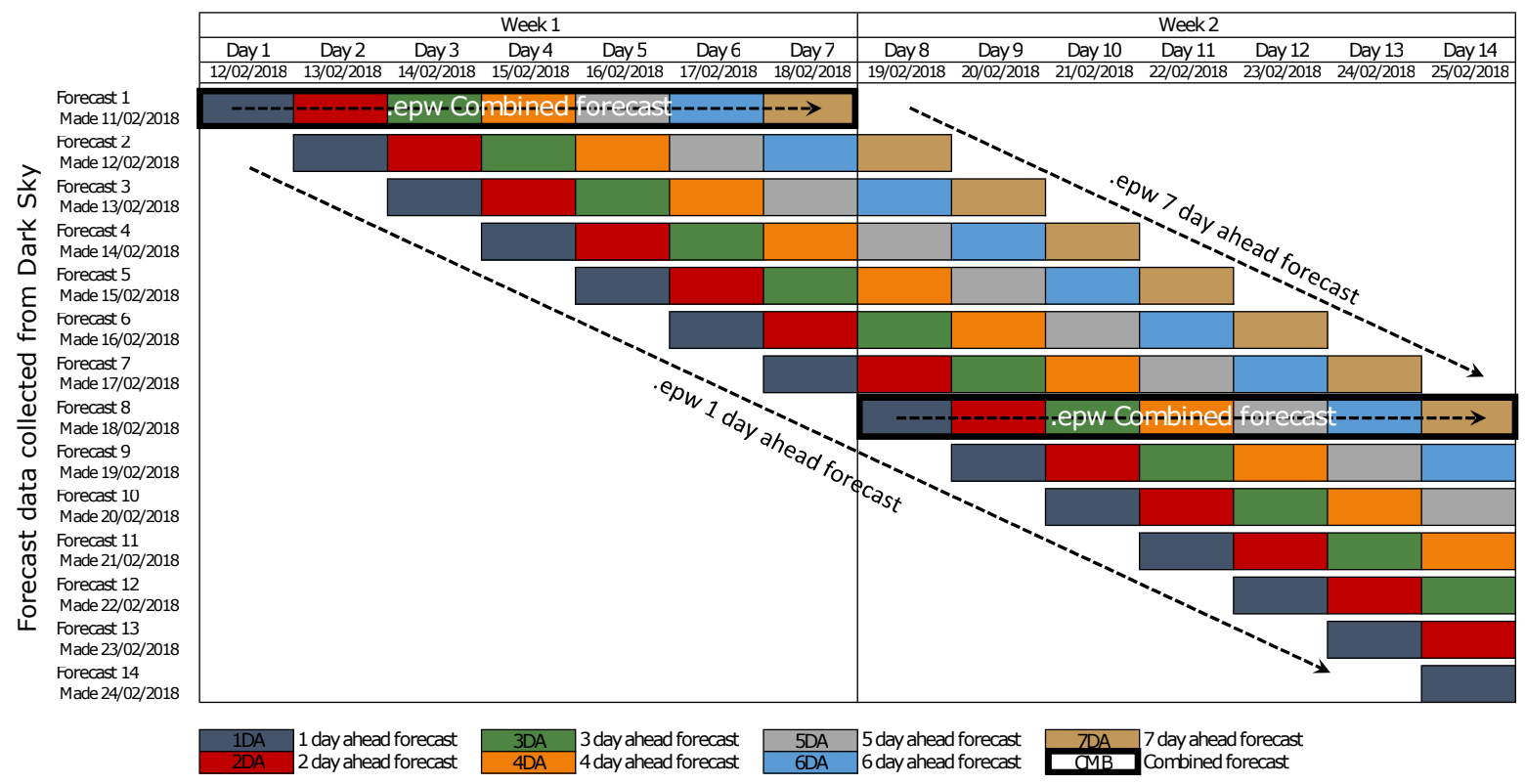

Figure 4. Organization of forecast data and construction of forecast weather files.
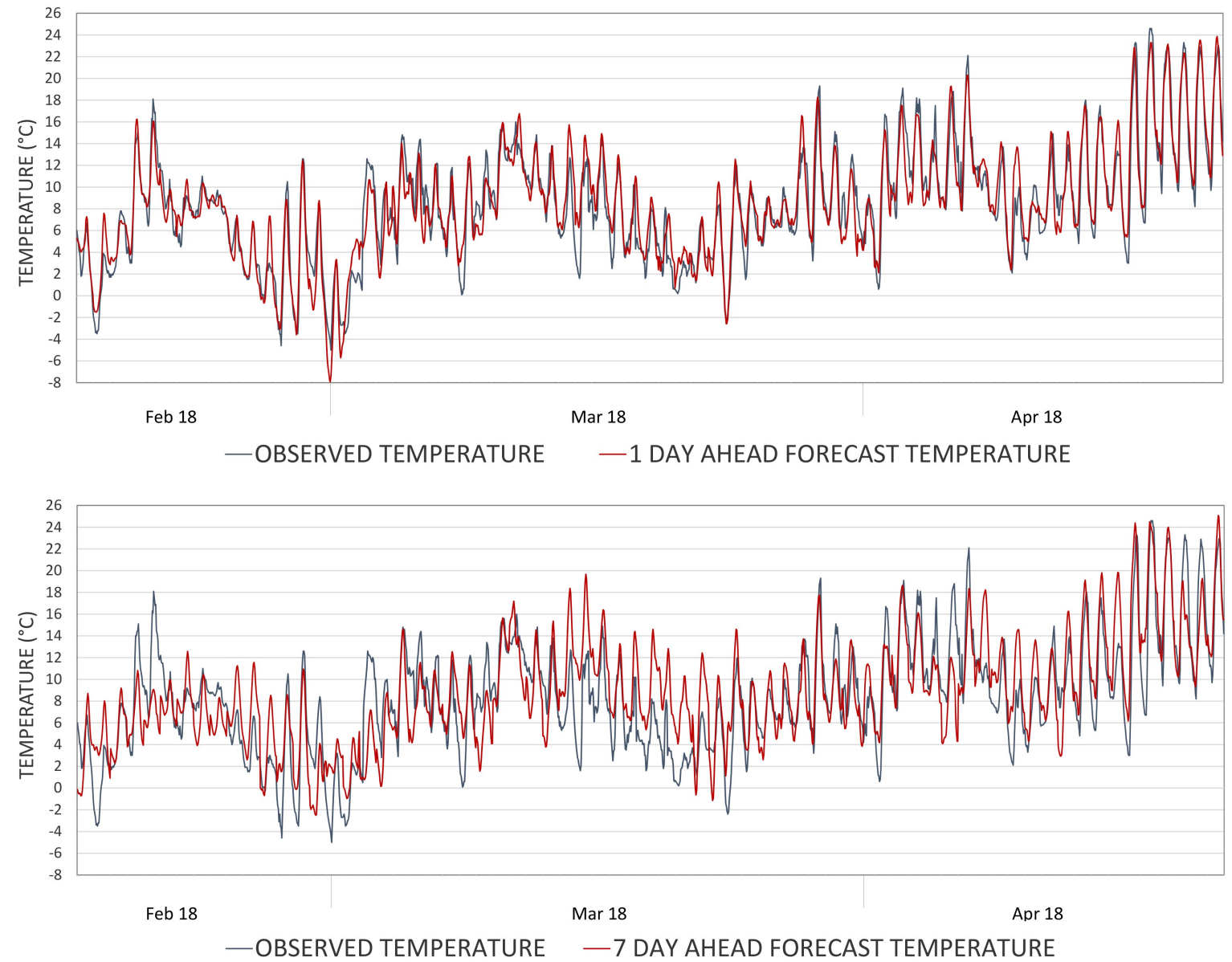

Figure 5. Comparison between observed and forecast outdoor temperature at Pamplona (12 February 2018-22 April 2018). Above: 1-day forecast outdoor temperature. Below: 7-day forecast outdoor temperature. 


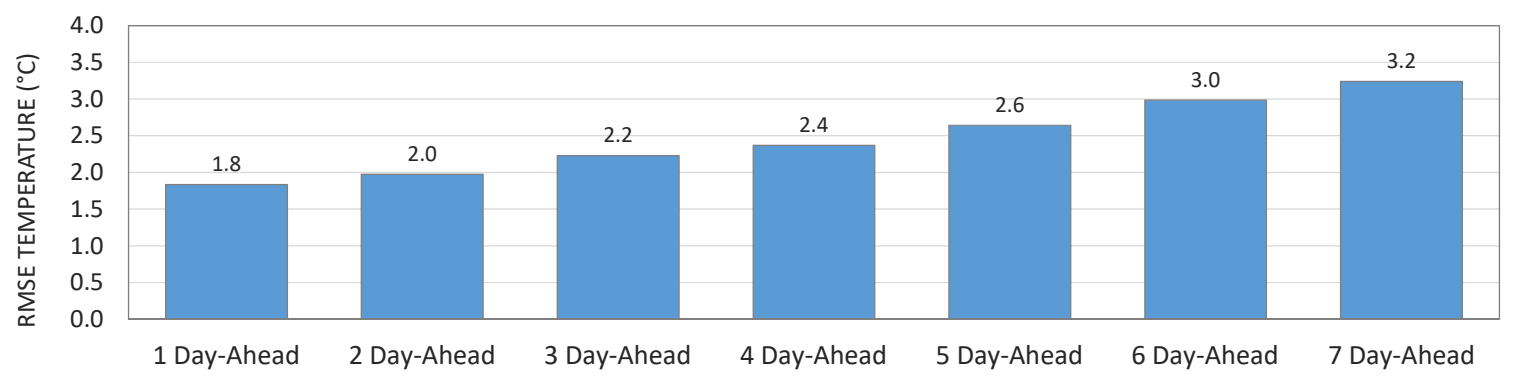

Figure 6. The temperature RMSE between Observation and Dark Sky forecasts from 1-day to 7-day (from 12 February 2018 to 22 April 2018).

\subsection{Sensitivity Analysis of Weather Parameters}

A sensitivity analysis is performed to analyze the significance of the weather parameters for this building. The methodology used is the Morris method [50] and the "relative deviation" method. The Morris method shows graphically the importance of each parameter in relation to the others using the mean $(\mu)$ and the standard deviation $(\sigma)$. "Relative deviation" method, described by Hamby [51], uses the coefficient of variation which relates the standard deviation $(\sigma)$ with the mean $(\mu)$. In this method, higher values are more sensitive than lower values.

The analysis is based on the real weather file generated with the observed data for the period of study and the change, one by one, of the weather parameters. The variation range of the parameters varies from $-10 \%$ to $10 \%$, step by $2.5 \%$. With this variations, it is assured that the minimum and maximum values for the parameters remain within the range of the real data for the period of study. Comparing the energy demand between the real weather simulation and the simulations with each changed parameters through the mean $(\mu)$ and the standard deviation $(\sigma)$, the significance of each weather parameter is obtained.

Figure 7 shows, for this period of study, that the outdoor temperature is the most sensitive weather parameter and has the greatest impact on the energy demand, as other studies have concluded [25,52]. For this reason, in the following analysis, only the outdoor temperature will be used. However, it should be noted that the forecast relative humidity, wind speed and wind direction are also introduced in the weather files and therefore their impact will be also reflected in the results.
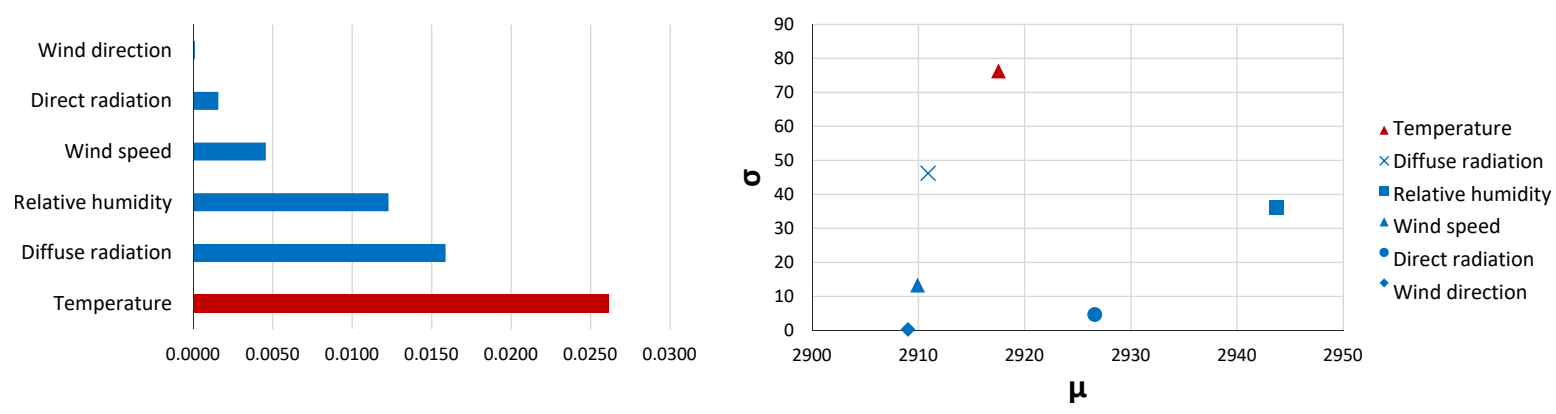

Figure 7. (left) “Relative deviation" method; (right): Morris method representation

In addition to the parameters used in this study, the graphs also show the sensitivity for the solar radiation. Diffuse solar radiation has a high impact on the energy demand of the building, just behind the temperature. The significance of this parameter and the impossibility to obtain it and the direct solar radiation from common and free-access APIs providers explain why solar radiation has not been included in this study. Direct and diffuse solar radiation particularities and calculation difficulties justify a dedicated study. 


\section{BEM Simulation and Error Metrics Calculation}

Figure 8 shows the methodology for the BEM simulation and the error metrics calculation. The simulation process starts with a first baseline simulation with the real weather data file. Then, iterative simulations are carried out for each forecast weather file. As outputs, the model is configured to provide: the outdoor temperature (OT) that corresponds to the measured hourly temperature for real weather data and forecast data for the different day-ahead forecast weather files; indoor temperature (IT), which is the mean hourly indoor temperature that the model provides with different weather files and energy demand (ED), which corresponds with the hourly heating or cooling energy demand to maintain the building between the temperature set-points.

The period of study covers three months of data with winter outdoor conditions but also spring conditions when cooling starts to be required. The HVAC system configuration of this building does not allow heating and cooling to occur simultaneously. For this reason, a classification of the weeks is made according to the prevailing demand for heating and cooling. The result is that among the 10 weeks of study, eight of them have heating needs and two have cooling needs.

As Figure 8 shows, the outputs from the simulations are used to perform an uncertainty analysis to provide the estimated error in the three parameters of analysis: outdoor temperature, indoor temperature and energy demand.

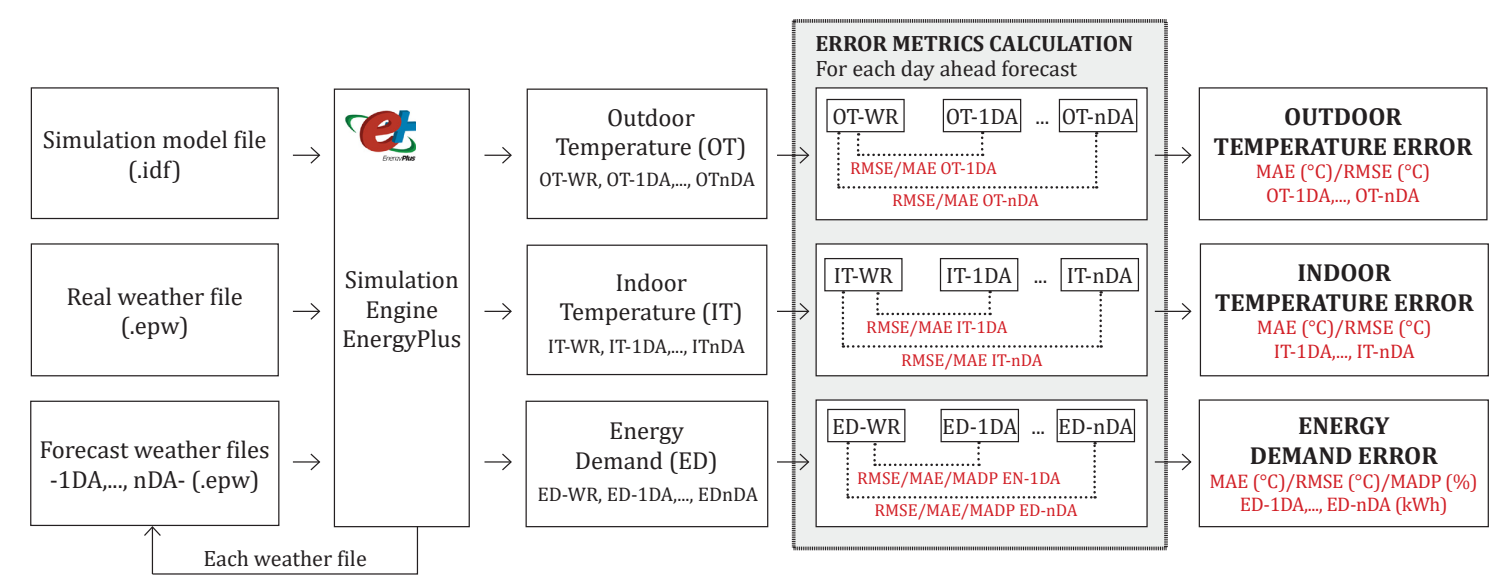

Figure 8. Building energy model (BEM) simulation and error metrics calculation scheme.

Three error metrics commonly used in the forecasting literature are used in this study: the Root Mean Square Error (RMSE) [25,53] (1) widely used for temperature forecast and the Mean Absolute Error (MAE) [25] (2) and the Mean Absolute Deviation Percent error (MADP) [54] (3) usually used for load forecasting. The equations of these error indexes are shown as:

$$
\begin{gathered}
R M S E=\left[\frac{1}{n} \sum_{i=1}^{n}\left(y_{i}-\hat{y}_{i}\right)^{2}\right]^{\frac{1}{2}}, \\
M A E=\frac{1}{n} \sum_{i=1}^{n}\left|y_{i}-\hat{y}_{i}\right|, \\
M A D P=\frac{\sum_{i=1}^{n}\left|y_{i}-\hat{y}_{i}\right|}{\sum_{i=1}^{n}\left|y_{i}\right|} .
\end{gathered}
$$

In the equations, $n$ is the number of observations, $y_{i}$ represents the actual measured data at the moment $i$ and $\hat{y}_{i}$ the predicted value at that moment.

Both RMSE and MAE measure the average magnitude of the error in the units of the variable of interest and range from 0 to $\infty$. They do not consider the direction of error, thus positive and negative errors are not cancelled. These indexes are used to indicate the error in ${ }^{\circ} \mathrm{C}$ for the outdoor temperature 
and the indoor temperature for the different forecasts. They are also used to analyze the error in the energy demand in $\mathrm{kWh}$.

For the energy demand results, the percentage error is also calculated using the ratio of the absolute error with the actual value through the Mean Absolute Deviation Percent $(M A D P)$. In the literature, the Mean Absolute Percentage Error (MAPE) is the most common measure used in the forecast error, but it has some disadvantages that affect this study: it is infinite when the actual values are zero and very large when actual values are close to zero what can misrepresent the overall error rate. To overcome this issue, the Mean Absolute Deviation Percent (MADP) is used instead of MAPE [54].

\section{Analysis of the Results}

For the analysis of the results, the error indexes showed in Section 4 are calculated using the hourly simulation outputs and comparing the results generated with the real weather data (WR) against the results generated with each forecast weather file (1DA to 7DA and CMB) for the three parameters: outdoor temperature, the mean indoor temperature and the energy demand. It is important to note that the analysis is performed with the hourly data and not with longer periods of time (days, weeks, months or for the whole period of study). The reason is because, depending on the weather forecast error, the error in the indoor conditions can produce an over or underestimation of the energy demand and, with longer periods of analysis, the results are accumulated and they compensate each other distorting the error. For this reason, to analyze the impact of the weather forecast on the energy demand prediction and avoid this cancellation effect, this methodology focuses on absolute energy demand differences in a hourly basis. Table 2 shows the results for the different indexes.

Table 2. Error metrics for forecast hourly outdoor temperature, mean hourly indoor temperature and hourly energy demand. RMSE: Root Mean Square Error; MAE: Mean Absolute Error; MADP: Mean Absolute Deviation Percentage; $1 D A$ : 1 day-ahead weather forecast; $C M B$ : Combined weather forecast.

\begin{tabular}{llllllllll}
\hline Parameter & Index & 1DA & 2DA & 3DA & 4DA & 5DA & 6DA & 7DA & CMB \\
\hline Outdoor temperature & $\operatorname{RMSE}\left({ }^{\circ} \mathrm{C}\right)$ & 1.82 & 1.98 & 2.2 & 2.4 & 2.72 & 3.01 & 3.44 & 2.68 \\
& $\operatorname{MAE}\left({ }^{\circ} \mathrm{C}\right)$ & 1.39 & 1.55 & 1.73 & 1.88 & 2.14 & 2.34 & 2.68 & 2.1 \\
\hline Indoor temperature & $\operatorname{RMSE~}\left({ }^{\circ} \mathrm{C}\right)$ & 0.33 & 0.36 & 0.41 & 0.48 & 0.5 & 0.58 & 0.66 & 0.44 \\
& $M A E\left({ }^{\circ} \mathrm{C}\right)$ & 0.25 & 0.28 & 0.32 & 0.37 & 0.39 & 0.44 & 0.54 & 0.33 \\
\hline \multirow{2}{*}{ Energy Demand } & $\operatorname{RMSE}(\mathrm{kWh})$ & 1.74 & 1.73 & 1.92 & 2.11 & 2.51 & 2.91 & 3.44 & 2.04 \\
& $M A E(\mathrm{kWh})$ & 1.33 & 1.32 & 1.49 & 1.61 & 1.97 & 2.1 & 2.81 & 1.55 \\
& $M A D P(\%)$ & 23 & 23 & 26 & 28 & 35 & 37 & 50 & 27 \\
\hline
\end{tabular}

Figure 9 shows the RMSE results for the outdoor and indoor temperature $\left({ }^{\circ} \mathrm{C}\right)$ and $M A E$ for the energy demand $(\mathrm{kWh})$ and it can be seen that, as the day-ahead forecast horizon increases, the error in the three parameters increases, showing a clear relationship between the error on outdoor conditions and the error on indoor conditions and energy demand of the model. Indeed, the correlation between the outdoor temperature RMSE and indoor temperature RMSE is 0.99 and between outdoor temperature RMSE and energy demand MAE is 0.95 . It indicates that both the error on the mean indoor temperature and the energy demand have a positive and a strong correlation with the errors on outdoor temperature. In the case of the combined case (CMB), the results show that the indicators stay in the mean with respect to the 1- to 7-day forecasts as it is a combination of daily forecasts.

In order to analyze and explain in depth the impact of using growing day-ahead weather forecasts in predicting energy demand, Figure 9 also shows the percentage error through the hourly MADP (\%) index for each day-ahead and the combined option. These two parameters have a strong and positive dependence, thus as the outdoor temperature RMSE increases with the growing day-ahead, so too does the percentage of hourly energy demand error $(M A D P)$. Figure 9 also represents the MADP $(\%)$ error for the whole period of study (70 days). As expected, using this period of analysis generates the compensation between the overestimated and underestimated energy demand, generating no 
correlation between the increasing day-ahead forecasts and the energy error. The cancel out effect also produces that the overall impact in the energy demand for the whole period to be very low compared to the hourly energy demand error.

Analyzing the results from Figure 9, we can conclude that, although the whole period MADP for the different day-ahead forecasts have low percentages, if the hourly absolute energy demand differences (hourly $M A D P$ ) are analyzed, the weather forecasts have a big impact (the lower percentage is $23 \%$ ), which grows along as the day-ahead forecasts increase (from $23 \%$ for the 1 -day forecast to $50 \%$ for a 7 -day forecast). For example, having a 1-day forecast means that, for this building and this weather provider, on average, a $23 \%$ hourly energy demand error is estimated between the 1 day-ahead energy demand prediction and the real building's behavior with real data.
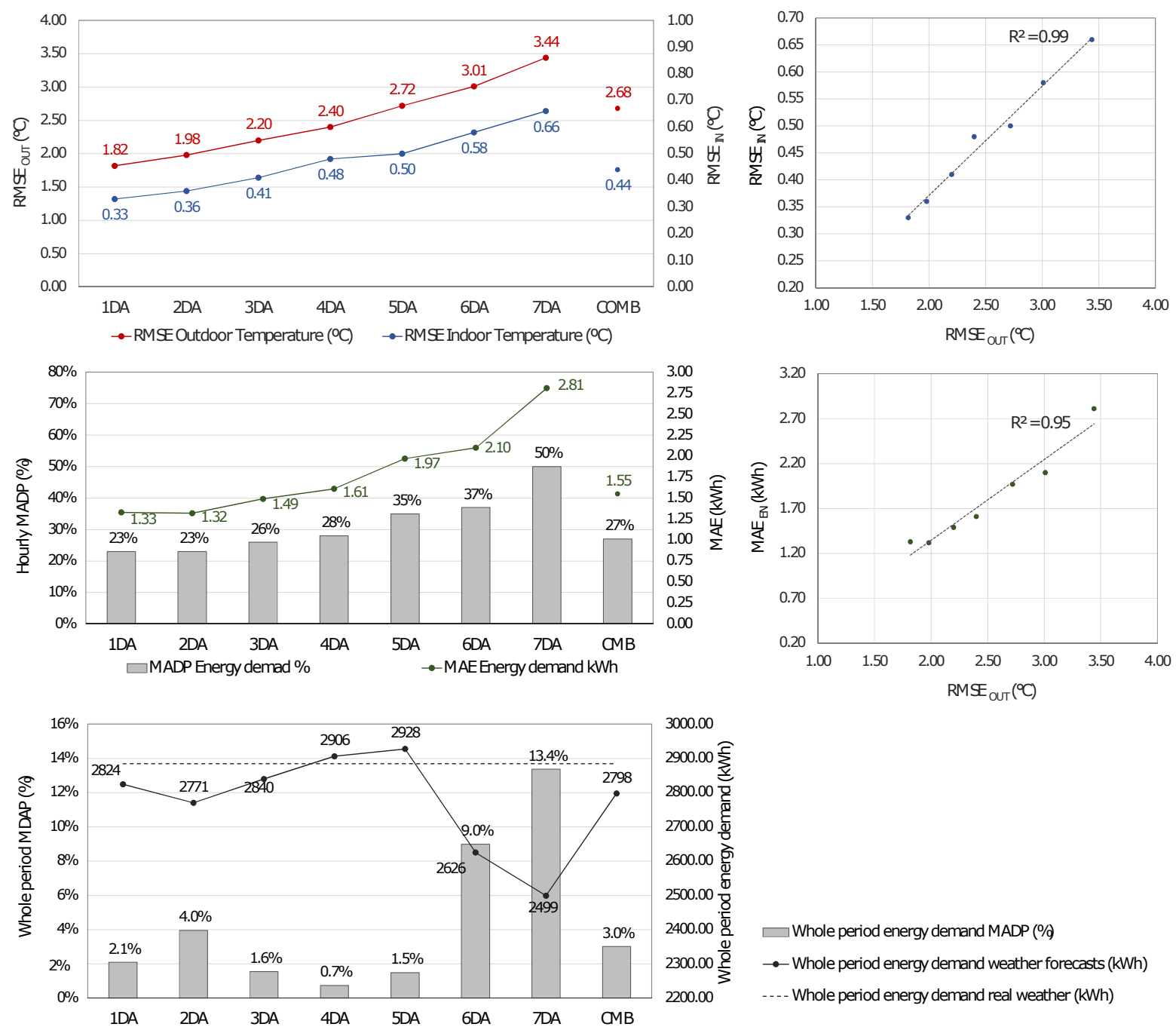

Figure 9. (above): comparison between hourly outdoor temperature error (RMSE) and hourly mean indoor temperature error (RMSE) for the different day-ahead forecasts. (middle): $M A E$ and $M A D P$ for hourly energy demand for the different day-ahead forecasts. (below): $M A D P$ and energy demand for the whole period of study for real weather and forecast weathers

\section{Application of the Methodology: Model Predictive Control (MPC) for Building Energy Flexibility}

The hourly impact of weather forecast in load prediction showed in previous analysis becomes crucial when the building interacts in the demand response or flexibility market. Model Predictive Control (MPC) and a simulation model are needed in these strategies to determine the building's 
capacity in providing energy flexibility to the grid. MPC is used to predict energy demand commonly for the next $24 \mathrm{~h}$ (but it could be longer) based on the expected conditions of building use, energy production and weather forecast. Subsequently, the building's flexibility hourly profile [30] with the maximum and minimum flexibility capacity over these $24 \mathrm{~h}$ and with 1-h granularity is computed, taking into account the comfort boundaries. However, there is an inherent uncertainty in the results due to several parameters, and one of them is the weather forecast. In this context, a deeper hourly analysis of the error between the energy demand provided by the real weather and the forecast weathers can be performed in order to add the estimate error due to weather forecast hour-by-hour in the flexibility map. For doing this, the data is classified hour-by-hour and the MAE index is calculated. Figure 10 shows the results for each hour and for the 7 day-ahead and the combined forecasts.

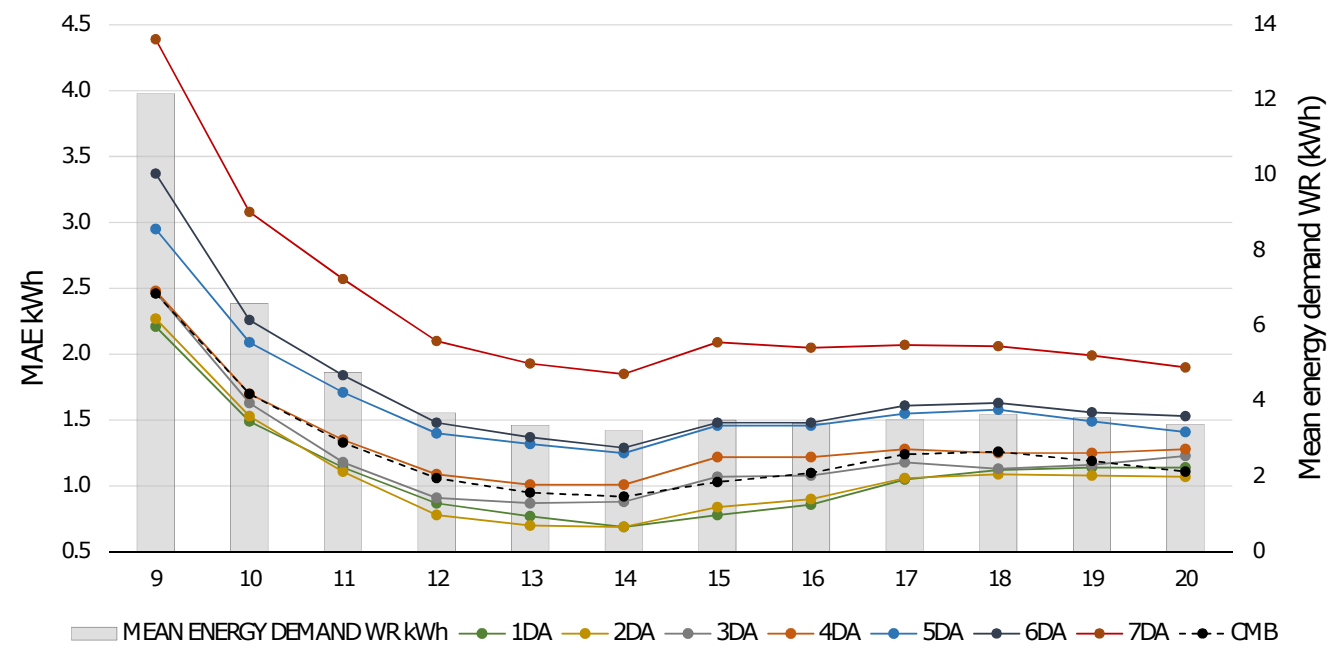

Figure 10. Error metric ( $M A E)$ for the energy demand hour-by-hour.

From Figure 10, we can conclude that, for the hour-by-hour analysis, the increasing error as the day-ahead forecast increases is maintained. All the day-ahead forecasts have a high error value at 9:00 a.m. because, during the night, the HVAC systems are switched off and, in the first morning hours, the energy demand to reach the set-point is very high. The result of this hour-by-hour methodology is a map of the error for each hour that complements the predicted hourly load provided in advance to the grid in a demand response or flexibility strategy.

\section{Conclusions}

This paper shows through a case study a methodology that characterizes the accuracy of the weather forecast provided for a specific location and analyzes the impact of this inaccuracy in the load prediction of a building. Each site will require a similar study case and the results should be analyzed in the same way. Therefore, the methodology can be extrapolated and applied on any other building, location or weather forecast provider.

Several error metrics have been used for the analysis or the results. RMSE and MAE characterized the hourly outdoor temperature and mean hourly indoor temperature errors $\left({ }^{\circ} \mathrm{C}\right)$ and the hourly energy demand error $(\mathrm{kWh})$ due to the use of increasing day-ahead weather forecasts. For the analysis of the hourly energy demand, MADP was also used to obtain the percentage error. On the other hand, it is remarkable that, to take full advantage of this methodology, it is important to perform the analysis using hourly data since longer periods generate a compensation between the overestimated and underestimated energy demand and distort the error.

The uncertainty analysis showed that, as the day-ahead forecast increases, the error in the three parameters grows, showing a positive and strong correlation between the error for outdoor conditions and those for indoor conditions and energy demand. Analyzing the hourly absolute energy demand 
errors, it can be concluded that for this case study the weather forecasts have an important impact (1-day forecast has a MADP of $23 \%$ between the energy demand prediction and the real one) and it grows as the number of days ahead are increased.

This effect is essential when the building interacts in the demand response or flexibility market and uses MPC to determine its capacity in providing hourly energy flexibility to the grid. For the application of this study in these growing scenarios, an energy demand error analysis is done classifying the data hour-by-hour and an hourly error profile is generated for the different day-ahead time horizons. The conclusion is that the hour-by-hour impact of the different weather forecast also grows and scales as the day-ahead increases. This effect is also seen with the pass of the hours during the day. The error increases as the hours pass because the forecast is done the night before; therefore, as time passes, the weather forecast is less accurate. The analysis demonstrated that this methodology acquires its full meaning when it is applied using predicted weather data that is close today.

The results and analysis done allow us to conclude that the sample selected in this paper is representative of the phenomena we try to study. As results have demonstrated, the three error metrics (RMSE, MAE and MADP) for the outdoor temperature, indoor temperature and energy demand, including the hour-by-hour analysis, have shown a clear and robust trend to grow as the day-ahead increases. This robust result enables us to scale and estimate the error in the predicted load produced for each day-ahead weather forecast.

Author Contributions: E.L.S. has supervised the methodology used in the article, performed the simulations and the analysis and has written the manuscript. H.D. has provided the weather data forecast. G.R.R. has developed the EnergyPlus model and participated in the data analysis. C.F.B. has developed the methodology that has been proposed in the article. All of the authors have revised and verified all the manuscript before sending it to the journal.

Funding: E.L.S, G.R.R. and C.F.B. work is funded by the research and innovation program Horizon 2020 of the European Union under the Grant No. 731211, project SABINA. H.D. work is supported by the Welsh Government's Sêr Cymru (Stars Wales) program.

Acknowledgments: This project has received funding from the European Union's Horizon 2020 research and innovation programme under Grant No. 731211, project SABINA. This study is also partly supported by the Welsh Government's Sêr Cymru (Stars Wales) program. Finally, we would like to thank the Welsh School of Architecture of the University of Cardiff, especially Huw Jenkins, for hosting the stay of the researchers Carlos Fernández Bandera and Eva Lucas Segarra.

Conflicts of Interest: The authors declare no conflict of interest.

\section{Abbreviations}

The following abbreviations are used in this manuscript:

$\begin{array}{ll}\text { APIs } & \text { Application Programming Interfaces } \\ \text { ASHRAE } & \text { American Society of Heating, Refrigerating and Air-Conditioning Engineers } \\ \text { BEM } & \text { Building Energy Model } \\ \text { CMB } & \text { Combined Weather File } \\ \text { DA } & \text { Day-Ahead } \\ \text { ED } & \text { Energy Demand } \\ \text { EPW } & \text { EnergyPlus Weather File } \\ \text { FEMP } & \text { Federal Energy Management Program } \\ \text { HVAC } & \text { Heating, Ventilation and Air Conditioning } \\ \text { IDF } & \text { EnergyPlus Input Files } \\ \text { IPMVP } & \text { International Performance Measurement and Verification Protocol } \\ \text { IT } & \text { Mean Indoor Temperature } \\ \text { JSON } & \text { JavaScript Object Notation } \\ \text { kWh } & \text { Kilowatt Hour } \\ \text { MADP } & \text { Mean Absolute Deviation Percentage } \\ \text { MAE } & \text { Mean Absolute Error } \\ \text { MAPE } & \text { Mean Absolute Percentage Error }\end{array}$


MARE Mean Absolute Relative Error

MPC Model Predictive Control

OT Outdoor Temperature

REST Representational State Transfer

RMSE Root Mean Square Error

WR Real Weather

XML Extensible Markup Language

\section{References}

1. European Parliament, Directive 2012/27/EU of the European Parliament and of the Council of 25 October 2012 on energy efficiency, amending Directives 2009/125/EC and 2010/30/EU and repealing Directives 2004/8/EC and 2006/32/EC. Off. J. Eur. Union 2012, L, 1-56.

2. Lazos, D.; Sproul, A.B.; Kay, M. Optimisation of energy management in commercial buildings with weather forecasting inputs: A review. Renew. Sustain. Energy Rev. 2014, 39, 587-603. [CrossRef]

3. Jankovic, L. Designing resilience of the built environment to extreme weather events. Sustainability 2018, 10, 141. [CrossRef]

4. Mohammadi, A.; Saghafi, M.R.; Tahbaz, M.; Nasrollahi, F. Effects of Vernacular Climatic Strategies (VCS) on Energy Consumption in Common Residential Buildings in Southern Iran: The Case Study of Bushehr City. Sustainability 2017, 9, 1950. [CrossRef]

5. Petersen, S.; Svendsen, S. Method for simulating predictive control of building systems operation in the early stages of building design. Appl. Energy 2011, 88, 4597-4606. [CrossRef]

6. OptiControl Project. Available online: http://opticontrol.ee.ethz.ch (accessed on 10 September 2018).

7. Oldewurtel, F.; Parisio, A.; Jones, C.; Morari, M.; Gyalistras, D.; Gwerder, M.; Stauch, V.; Lehmann, B.; Wirth, K. Energy efficient building climate control using stochastic model predictive control and weather predictions. In Proceedings of the 2010 American Control Conference, Baltimore, MD, USA, 30 June-2 July 2010; IEEE Service Center: Piscataway, NJ, USA, 2010; pp. 5100-5105.

8. Gyalistras, D.; Gwerder, M. Use of Weather and Occupancy Forecasts for Optimal Building Climate Control (OptiControl): Two Years Progress Report Main Report; Terrestrial Systems Ecology ETH Zurich R\&D HVAC Products, Building Technologies Division, Siemens Switzerland Ltd.: Zug, Switzerland, 2010; p. 83.

9. Sturzenegger, D.; Gyalistras, D.; Gwerder, M.; Sagerschnig, C.; Morari, M.; Smith, R.S. Model Predictive Control of a Swiss office building. In Proceedings of the Clima-Rheva World Congress, Prague, Czech Republic, 16-19 June 2013; pp. 3227-3236.

10. Gwerder, M.; Gyalistras, D.; Sagerschnig, C.; Smith, R.; Sturzenegger, D. Final Report: Use of Weather and Occupancy Forecasts for Optimal Building Climate Control-Part II: Demonstration (OptiControl-II); Automatic Control Laboratory, ETH Zurich: Zug, Switzerland, 2013; p. 156.

11. Cigler, J.; Gyalistras, D.; Široky, J.; Tiet, V.; Ferkl, L. Beyond theory: The challenge of implementing model predictive control in buildings. In Proceedings of the 11th Rehva World Congress, Clima, 2013, Prague, Czech Republic, 16-19 June 2013; Volume 250.

12. Jensen, S.Ø.; Marszal-Pomianowska, A.; Lollini, R.; Pasut, W.; Knotzer, A.; Engelmann, P.; Stafford, A.; Reynders, G. IEA EBC annex 67 energy flexible buildings. Energy Build. 2017, 155, 25-34. [CrossRef]

13. Hedegaard, R.E.; Pedersen, T.H.; Petersen, S. Multi-market demand response using economic model predictive control of space heating in residential buildings. Energy Build. 2017, 150, 253-261. [CrossRef]

14. Heidrich, T.; Grobe, J.; Meschede, H.; Hesselbach, J. Economic Multiple Model Predictive Control for HVAC Systems-A Case Study for a Food Manufacturer in Germany. Energies 2018, 11, 3461. [CrossRef]

15. Ruiz, G.R.; Bandera, C.F.; Temes, T.G.A.; Gutierrez, A.S.O. Genetic algorithm for building envelope calibration. Appl. Energy 2016, 168, 691-705. [CrossRef]

16. Ruiz, G.R.; Bandera, C.F. Analysis of uncertainty indices used for building envelope calibration. Appl. Energy 2017, 185, 82-94. [CrossRef]

17. Fernández Bandera, C.; Ramos Ruiz, G. Towards a New Generation of Building Envelope Calibration. Energies 2017, 10, 2102. [CrossRef]

18. Ramos Ruiz, G.; Lucas Segarra, E.; Fernández Bandera, C. Model Predictive Control Optimization via Genetic Algorithm Using a Detailed Building Energy Model. Energies 2019, 12, 34. [CrossRef] 
19. Sandels, C.; Widén, J.; Nordström, L.; Andersson, E. Day-ahead predictions of electricity consumption in a Swedish office building from weather, occupancy, and temporal data. Energy Build. 2015, 108, $279-290$. [CrossRef]

20. Hossa, T.; Filipowska, A.; Fabisz, K. The comparison of medium-term energy demand forecasting methods for the need of microgrid management. In Proceedings of the 2014 IEEE International Conference on Smart Grid Communications (SmartGridComm), Venice, Italy, 3-6 November 2014; pp. 590-595.

21. Yuce, B.; Mourshed, M.; Rezgui, Y. A smart forecasting approach to district energy management. Energies 2017, 10, 1073. [CrossRef]

22. Agüera-Pérez, A.; Palomares-Salas, J.C.; de la Rosa, J.J.G.; Florencias-Oliveros, O. Weather forecasts for microgrid energy management: Review, discussion and recommendations. Appl. Energy 2018, 228, 265-278. [CrossRef]

23. Henze, G.P.; Kalz, D.E.; Felsmann, C.; Knabe, G. Impact of forecasting accuracy on predictive optimal control of active and passive building thermal storage inventory. HVACER Res. 2004, 10, 153-178.

24. Oldewurtel, F.; Parisio, A.; Jones, C.N.; Gyalistras, D.; Gwerder, M.; Stauch, V.; Lehmann, B.; Morari, M. Use of model predictive control and weather forecasts for energy efficient building climate control. Energy Build. 2012, 45, 15-27. [CrossRef]

25. Zhao, J.; Liu, X. A hybrid method of dynamic cooling and heating load forecasting for office buildings based on artificial intelligence and regression analysis. Energy Build. 2018, 174, 293-308. [CrossRef]

26. Du, H.; Jones, P.; Ng, B. Understanding the reliability of localized near future weather data for building performance prediction in the UK. In Proceedings of the 2016 IEEE International Smart Cities Conference (ISC2), Trento, Italy, 12-15 September 2016; pp. 1-4.

27. Du, H.; Barclay, M.; Jones, P. Generating High Resolution Near-Future Weather Forecasts for Urban Scale Building Performance Modelling. In Proceedings of the Building Simulation 2017: 15th Conference of International Building Performance Simulation Association, San Francisco, CA, USA, 7-9 August 2017.

28. Du, H.; Segarra, E.L.; Bandera, C.F. Development of a REST API for obtaining site-specific historical and near-future weather data in EPW format. In Proceedings of the BSO 2018 4th Building Simulation and Optimization Conference, Cambridge, UK, 11-12 September 2018.

29. Conejo, A.J.; Sioshansi, R. Rethinking restructured electricity market design: Lessons learned and future needs. Int. J. Electr. Power Energy Syst. 2018, 98, 520-530. [CrossRef]

30. Péan, T.Q.; Torres, B.; Salom, J.; Ortiz, J. Representation of daily profiles of building energy flexibility. In Proceedings of the eSim, Montréal, QC, Canada, 9-10 May 2018.

31. Guglielmetti, R.; Macumber, D.; Long, N. OpenStudio: An open source integrated analysis platform. In Proceedings of the 12th Conference of International Building Performance Simulation Association, Sydney, Australia, 14-16 November 2011.

32. Crawley, D.B.; Lawrie, L.K.; Winkelmann, F.C.; Buhl, W.F.; Huang, Y.J.; Pedersen, C.O.; Strand, R.K.; Liesen, R.J.; Fisher, D.E.; Witte, M.J.; et al. EnergyPlus: Creating a new-generation building energy simulation program. Energy Build. 2001, 33, 319-331. [CrossRef]

33. Crawley, D.B.; Lawrie, L.K.; Pedersen, C.O.; Winkelmann, F.C.; Witte, M.J.; Strand, R.K.; Liesen, R.J.; Buhl, W.F.; Huang, Y.J.; Henninger, R.H.; et al. EnergyPlus: An update. Proc. SimBuild 2004, 1, 1-8.

34. Recast, E. Directive 2010/31/EU of the European Parliament and of the Council of 19 May 2010 on the energy performance of buildings (recast). Off. J. Eur. Union 2010, 18, 2010.

35. IPMVP Committee. International Performance Measurement and Verification Protocol: Concepts and Options for Determining Energy and Water Savings; Technical Report; National Renewable Energy Lab.: Golden, CO, USA, 2001; Volume I.

36. FEMP, M. Guidelines: Measurement and Verification for Federal Energy Projects; Version 3.0.; Energy Efficiency and Renewable Energy: Washington, DC, USA, 2008.

37. FEMP, M. Guidelines: Measurement and Verification for Federal Energy Projects; Version 4.0; Energy Efficiency and Renewable Energy: Washington, DC, USA, 2015.

38. ASHRAE. Guideline 14-2002, Measurement of Energy and Demand Savings; ASHRAE: Atlanta, GA, USA, 2002; p. 22.

39. Ruiz, G.R.; Bandera, C.F. Validation of Calibrated Energy Models: Common Errors. Energies 2017, $10,1587$. [CrossRef] 
40. del Estado, Boletín Oficial. Real Decreto 1027/2007, Reglamento de Instalaciones Térmicas en los Edificios (RITE). 2007. Available online: https:/ / www.iberley.es/legislacion/real-decreto-1027-2007-20-julreglamento-instalaciones-termicas-edificios-4817359 (accessed on 10 September 2018).

41. DOE, E. Auxiliary Programs: EnergyPlus ${ }^{T M}$ Version 8.9.0 Documentation; US Department of Energy: Washington, DC, USA, 2018.

42. AEMET, Agencia Estatal de Meteorología. Available online: http://aemet.es (accessed on 10 September 2018).

43. Meteorologisk Institutt. Available online: https://api.met.no (accessed on 10 September 2018).

44. Open Weather Map. Available online: https://openweathermap.org/api (accessed on 10 September 2018).

45. Weatherbit.io. Available online: https://www.weatherbit.io/api (accessed on 10 September 2018).

46. The Dark Sky Company, LLC. Available online: https://darksky.net/dev (accessed on 10 September 2018).

47. Weather Underground. Available online: https://www.wunderground.com/weather/api/ (accessed on 10 September 2018).

48. Dimas, F.; Gilani, S.; Aris, M. Hourly solar radiation estimation from limited meteorological data to complete missing solar radiation data. In Proceedings of the International Conference on Enviroment Science and Engineering IPCBEE, Singapore, 26-28 February 2011; Volume 2628, p. 48.

49. Spokas, K.; Forcella, F. Estimating hourly incoming solar radiation from limited meteorological data. Weed Sci. 2006, 54, 182-189. [CrossRef]

50. Morris, M.D. Factorial sampling plans for preliminary computational experiments. Technometrics 1991, 33, 161-174. [CrossRef]

51. Hamby, D. A review of techniques for parameter sensitivity analysis of environmental models. Environ. Monit. Assess. 1994, 32, 135-154. [CrossRef] [PubMed]

52. Zhao, J.; Duan, Y.; Liu, X. Uncertainty Analysis of Weather Forecast Data for Cooling Load Forecasting Based on the Monte Carlo Method. Energies 2018, 11, 1900. [CrossRef]

53. Mirakyan, A.; Meyer-Renschhausen, M.; Koch, A. Composite forecasting approach, application for next-day electricity price forecasting. Energy Econ. 2017, 66, 228-237. [CrossRef]

54. Petojević, Z.; Gospavić, R.; Todorović, G. Estimation of thermal impulse response of a multi-layer building wall through in-situ experimental measurements in a dynamic regime with applications. Appl. Energy 2018, 228, 468-486. [CrossRef] 